\title{
Perda de participação do emprego industrial e evolução do setor comercial no Brasil
}

\section{Introdução}

Luciano Nakabashi* Gabriel Porcile* Márcio José V argas da Cruz Fábio Dória Scatolin ${ }^{* * *}$

O objetivo deste artigo é discutir as conseqüências da perda de participação do emprego industrial no emprego total e a importância da indústria no crescimento, além de algumas tendências na composição setorial do emprego e dos salários no setor comercial brasileiro e suas implicações para o crescimento e o bem-estar.

Considerando a importância que o setor de serviços vem alcançando na geração de novas vagas de emprego, tornando-se um dos principais motores potenciais de crescimento econômico, é crucial a realização de uma análise mais detalhada dos segmentos do setor de serviços que vem ganhando e perdendo participação.

No presente estudo, o foco de análise está nas mudanças da participação do emprego no segmento comercial, visto o ganho de importância deste nos últimos anos. Em estudos futuros serão feitas análises da evolução do emprego nos outros segmentos do setor de serviços.

\section{Perda da participação do emprego industrial no emprego total}

PALMA (2005), utilizando como conceito de desindustrialização a perda de participação do emprego da indústria no total de emprego da economia, observa que alguns países da América Latina como Brasil, Argentina, Chile e Uruguai, por razões diferentes dos países avançados, passaram por um processo de desindustrialização rápida nos anos oitenta.

Pode-se observar, pelos dados apresentados na Tabela 1, que o Cone Sul e o Brasil sofreram uma significativa perda de participação do emprego industrial em relação ao emprego total da economia entre 1960-1998:

Eles mostram que o Cone Sul da América Latina e o Brasil passaram da segunda colocação, no que se refere à participação do emprego industrial no total de empregos da economia, para penúltimo, no período considerado. Em 1998, a região fica atrás, até mesmo,

\footnotetext{
* Professor do Departamento de Economia da UFPR - luciano.nakabashi@ufpr.br

** Professor do Departamento de Economia da UFPR e Pesquisador do CNPq - porcile@uol.com.br

*** Professor do Departamento de Economia da UFPR - marciocruz@ufpr.br

**** Professor do Departamento de Economia da UFPR - $\underline{\text { scatolin@ } \mathrm{ufpr} . \mathrm{br}}$
} 
da média das economias em desenvolvimento ${ }^{15}$. Essa perda de participação do emprego industrial no emprego total pode ter impactos no crescimento econômico de longo prazo.

Tabela 1. Emprego industrial (\% do total)

\begin{tabular}{lrrrrr}
\hline Região & 1960 & 1970 & 1980 & 1990 & 1998 \\
\hline África Sub-Sahariana & 4,4 & 4,8 & 6,2 & 5,5 & 5,5 \\
América Latina e Caribe & 15,4 & 16,3 & 16,5 & 16,8 & 14,2 \\
Cone Sul e Brasil & 17,4 & 17,2 & 16,2 & 16,6 & 11,8 \\
Ásia Ocidental e Norte da África & 7,9 & 10,7 & 12,9 & 15,1 & 15,3 \\
Sul da Ásia & 8,7 & 9,2 & 10,7 & 13 & 13,9 \\
Leste da Ásia (exceto China e Japão) & 10 & 10,4 & 15,8 & 16,6 & 14,9 \\
NIES & 10,5 & 12,9 & 18,5 & 21 & 16,1 \\
China & 10,9 & 11,5 & 10,3 & 13,5 & 12,3 \\
Terceiro Mundo & 10,2 & 10,8 & 11,5 & 13,6 & 12,5 \\
Primeiro Mundo & 26,5 & 26,8 & 24,1 & 20,1 & 17,3 \\
\hline
\end{tabular}

Fonte: PALMA (2005), onde o autor faz uso de estatísticas do Banco de Dados da ILO. Médias regionais são ponderadas pela população economicamente ativa.

KALDOR (1962) argumenta, em seu trabalho clássico, que a indústria é o lócus por excelência do progresso técnico. FURTADO (1972), também enfatiza esse ponto no caso da economia brasileira: “... a atividade industrial condiciona o comportamento global da economia e os investimentos industriais são o canal por onde penetra o progresso tecnológico." (p. 34). HIRSCHMAN (1958) já tinha sugerido um argumento similar, apontando que a indústria teria maior potencial para gerar efeitos de arraste (linkages) sobre o conjunto da economia.

Espera-se que esses efeitos sejam ainda mais relevantes quando se considera a indústria de transformação, por ser a parte mais dinâmica da indústria e gerar maiores efeitos de encadeamento com outros segmentos e setores, além de ter um maior potencial de crescimento da produtividade. A análise dos dados no que concerne a relação entre a taxa de crescimento da produtividade industrial de uma série de países da América Latina e Sudeste

15 Economias incluídas sob o título "Terceiro Mundo": África do Sub-Saara: Benin, Botsuana, Burkina Faso, Camarões, República Central Africana, Chade, República Democrática do Congo, Costa do Marfim, Gabão, Gana, Quênia, Lesotho, Malawi, Mali, Mauritânia, Maurício, Nigéria, República do Congo, Ruanda, Senegal, África do Sul, Togo, Zâmbia e Zimbábue. América Latina e Caribe: Argentina, Brasil, Chile, Colômbia, Costa Rica, República Dominicana, Equador, El Salvador, Guatemala, Honduras, Jamaica, México, Nicarágua, Panamá, Paraguai, Peru e Uruguai (dentro dessa categoria, a subcategoria "Cone Sul" inclui Argentina, Chile e Uruguai). Ásia Ocidental e África do Norte: Algéria, Egito, Marrocos, Oman, Arábia , Arunísia e Turquia. Sul da Ásia: Bangladesh, Índia, Paquistão e Sri Lanka. Leste Asiático: Hong Kong SAR, Indonésia, Malásia, Filipinas, República da Coréia, Singapura, Tailândia e Taiwan Província da China (dentro dessa categoria, a subcategoria NIEs 1 inclui: Hong Kong SAR, República da Coréia, Cingapura e Taiwan (Província da China).

Economias incluídas sob o título "Primeiro Mundo": Austrália, Áustria, Bélgica, Canadá, Dinamarca, Finlândia, França, Grécia, Itália, Japão, Luxemburgo, Holanda, Nova Zelândia, Noruega, Portugal, Espanha, Suécia, Reino Unido e Estados Unidos. 
Asiático com as respectivas taxas de crescimento de suas indústrias de transformação, no gráfico 1, dá sustentação aos argumentos teóricos de KALDOR (1962) e HIRSCHMAN (1958) listados anteriormente, além de estar de acordo com os resultados encontrados por PIEPER (1998).

\section{Gráfico 1. Relação entre as taxas de crescimento da produtividade industrial da indústria de transformação: 1986-2004}

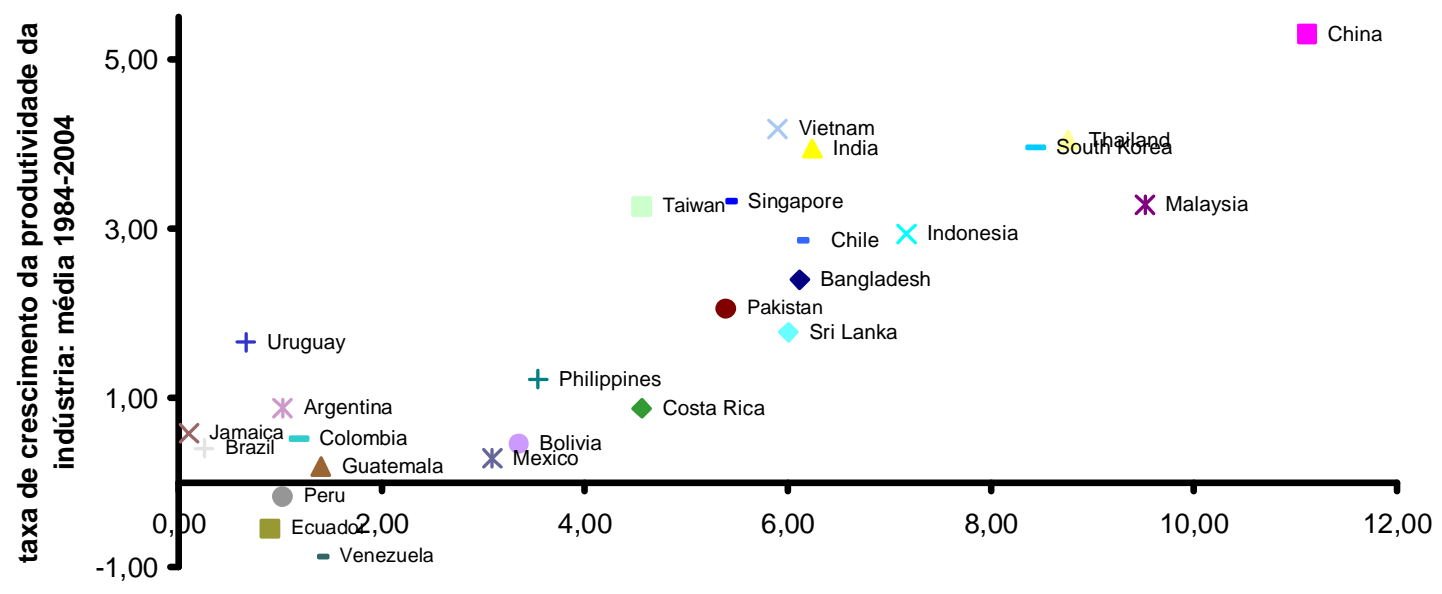

taxa de crescimento da indústria de transformação: média 1984-2004

Fonte: elaboração própria a partir dos dados de Groningen Growth and Development Centre Total Economy Database, January 2007 e OIT (Organização Internacional do Trabalho)

O Gráfico 1 mostra a relação positiva entre a taxa de crescimento da produtividade industrial e a taxa de crescimento da indústria de transformação. Portanto, os países que tiveram maior crescimento da indústria de transformação foram os mesmos que apresentaram um elevado crescimento da produtividade do setor industrial. Essas evidências também estão de acordo com alguns resultados encontrados por FEIJÓ, CARVALHO e RODRIGUEZ (2003) que apontam para a importância que a indústria tem no processo de inovação e, conseqüentemente, no aumento da produtividade.

No mesmo gráfico, é importante observar a existência de uma aglomeração de países latino americanos no canto inferior-esquerdo, enquanto que os países do sudeste asiático se concentram na parte superior-direita. Note-se, em particular, que a economia brasileira tem um dos piores desempenhos em relação às duas variáveis.

Como o crescimento da produtividade é um dos elementos mais importantes sobre a determinação do crescimento do PIB, como já ressaltado por vários autores ortodoxos e heterodoxos, a relação entre a taxa de crescimento do PIB da indústria de transformação e do PIB total também é positiva, como se pode ver no gráfico 2. 


\section{Gráfico 2. Relação entre as taxas de crescimento do PIB e da indústria de transformação: 1986-2004}

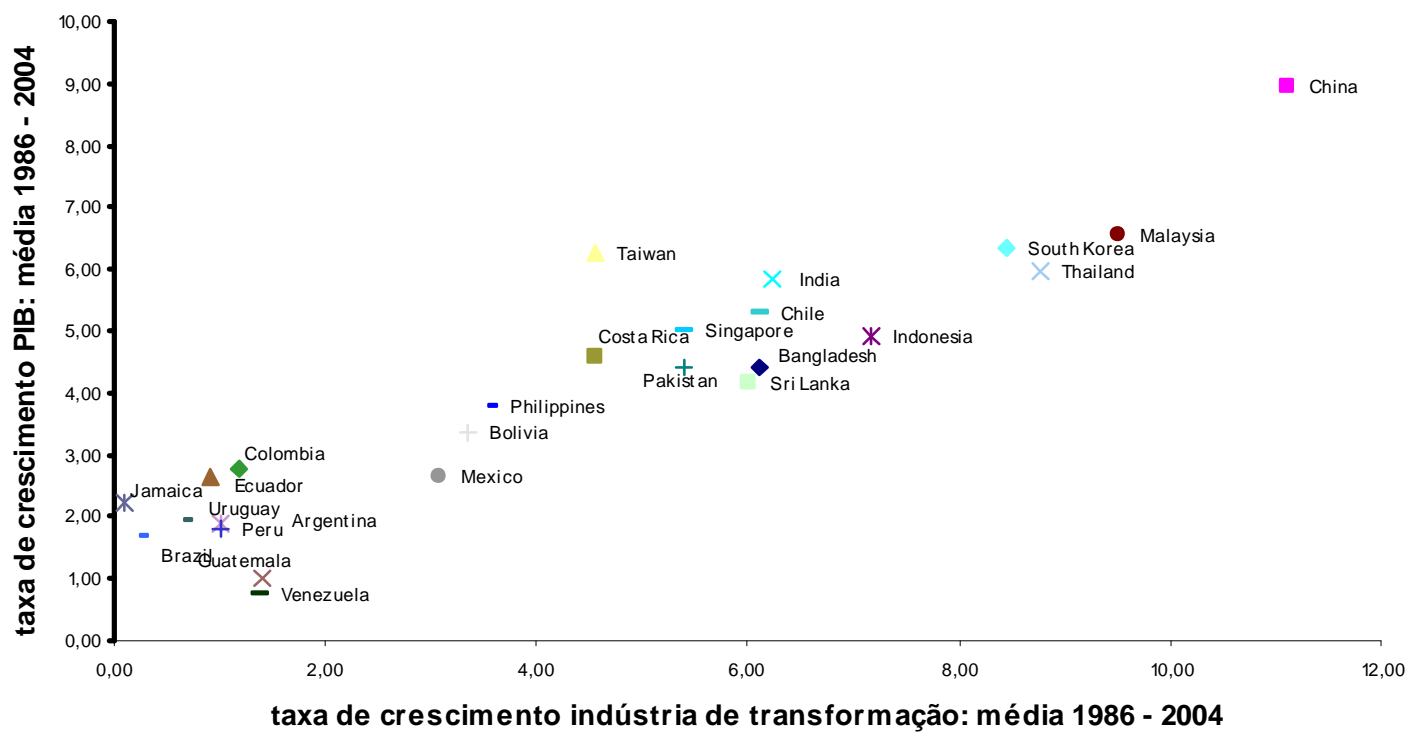

Fonte: elaboração própria a partir dos dados de Groningen Growth and Development Centre Total Economy Database, January 2007 e OIT (Organização Internacional do Trabalho)

Assim, os países com maiores taxas de crescimento da indústria de transformação foram os que experimentaram taxas de crescimento do PIB mais elevadas. No gráfico 2 também ocorre uma concentração de países latino americanos no canto inferior-esquerdo, enquanto que os países do sudeste asiático se concentram na parte superior-direita. Novamente, a economia brasileira se encontra em uma das piores posições em relação aos outros países. Mesmo considerando apenas os países da América Latina, o Brasil apresentou um desempenho relativo muito fraco entre 1986 e 2004.

Em relação ao dinamismo e crescimento da produtividade, o contrário acontece com o setor serviços quando comparado com o setor industrial. BAUMOL (1967) observara que o setor serviços tende a concentrar empregos e que os mesmos são de produtividade menor do que os da indústria. Assim, as evidências sugerem que os aumentos de produtividade e o crescimento do PIB estão estreitamente relacionados ao peso e ao crescimento da indústria de transformação na economia.

\section{3. $O$ setor de serviços da economia brasileira}

Dado o processo natural de desindustrialização, é fundamental que o setor serviços passe a desempenhar um papel dinâmico no crescimento. À medida que se perdem empregos na indústria, a qualidade dos empregos nos serviços determina as tendências dominantes na 
economia. É importante que seu desenvolvimento ocorra, principalmente, em segmentos que exijam alta qualificação e maior produtividade.

A desagregação da RAIS nos dá uma idéia do que está ocorrendo com o nível de emprego formal no setor de serviços. Esse setor ampliou sua participação no total de empregos da economia de 65,59\% para 72,39\%, entre 1985 e 2005, com a criação líquida de quase 11 milhões de novos empregos.

De todos os segmentos do setor de serviços o que mais se expandiu na geração de empregos foi o da Administração Pública com um crescimento, em termos absolutos, de 3.146 mil empregos, entre 1985 e 2005 (gráfico 3). O segmento que absorveu o segundo maior contingente foi o comércio varejista com um ganho líquido de 2.934 mil empregos. Adicionalmente, foi o segmento do setor de serviços que mais aumentou sua participação relativa, passando de $16,21 \%$ para $21 \%$ no total desse setor, no período $1985-2005$.

\section{Gráfico 3. Estoque de emprego formal nos segmentos do setor de serviços (1985-2005)}

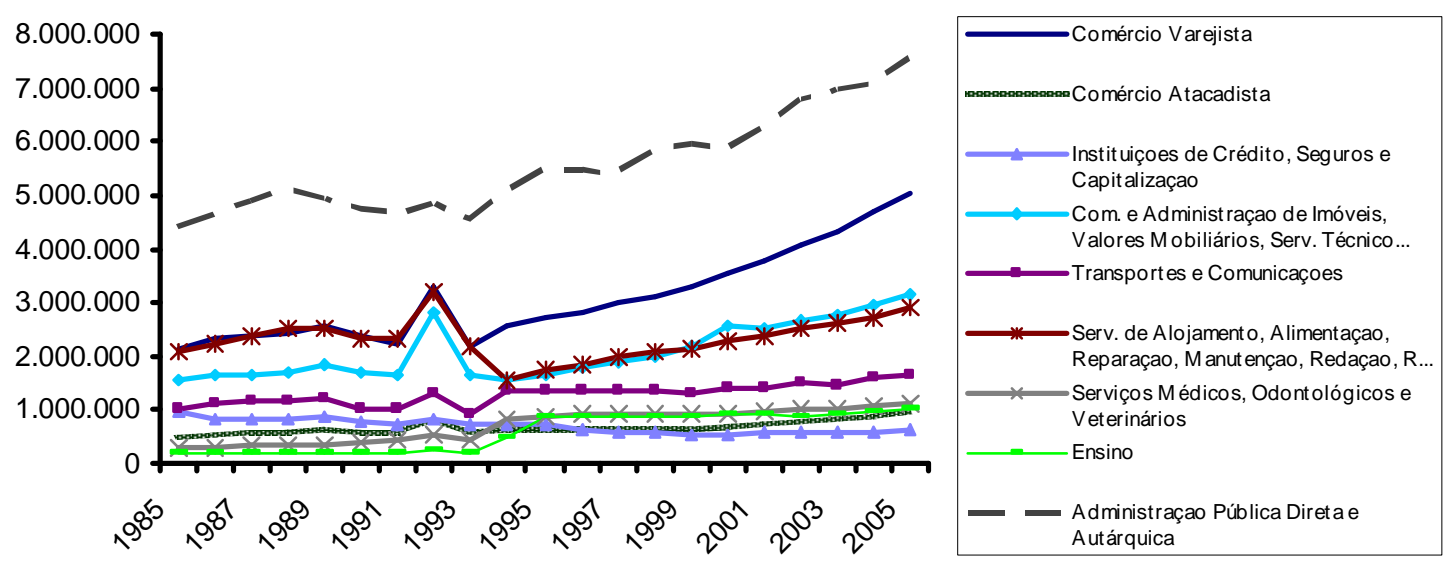

Fonte: Elaboração própria a partir de dados do Ministério do Emprego e Trabalho (RAIS)

O segmento de comércio e administração de imóveis, valores mobiliários e serviço técnico também teve destaque na geração de emprego, no período analisado (1.620 mil novos empregos). Sua participação no total de empregos formais do setor de serviços passou de 11,71\% para 13,09\%, entre 1985 e 2005 . Outro segmento de destaque foi o de comércio atacadista, com uma criação de 450 mil novos empregos e um aumento de participação de $0,33 \%$, no período. Desse modo, os segmentos que mais cresceram foram aqueles que apresentam menor produtividade.

Dando um maior foco nas mudanças da participação do emprego no segmento comercial, visto o ganho de importância deste nos últimos anos, no gráfico 4, apresenta-se a evolução do pessoal ocupado no comércio brasileiro de acordo com a seguinte divisão: 1) 
comércio de veículos e motocicletas; 2) comércio por atacado; e 3) comércio varejista. De acordo com essa divisão, podemos ver que não ocorreram grandes modificações entre 19962005.

Gráfico 4. Evolução do emprego formal no segmento comercial no Brasil: 1996-2005

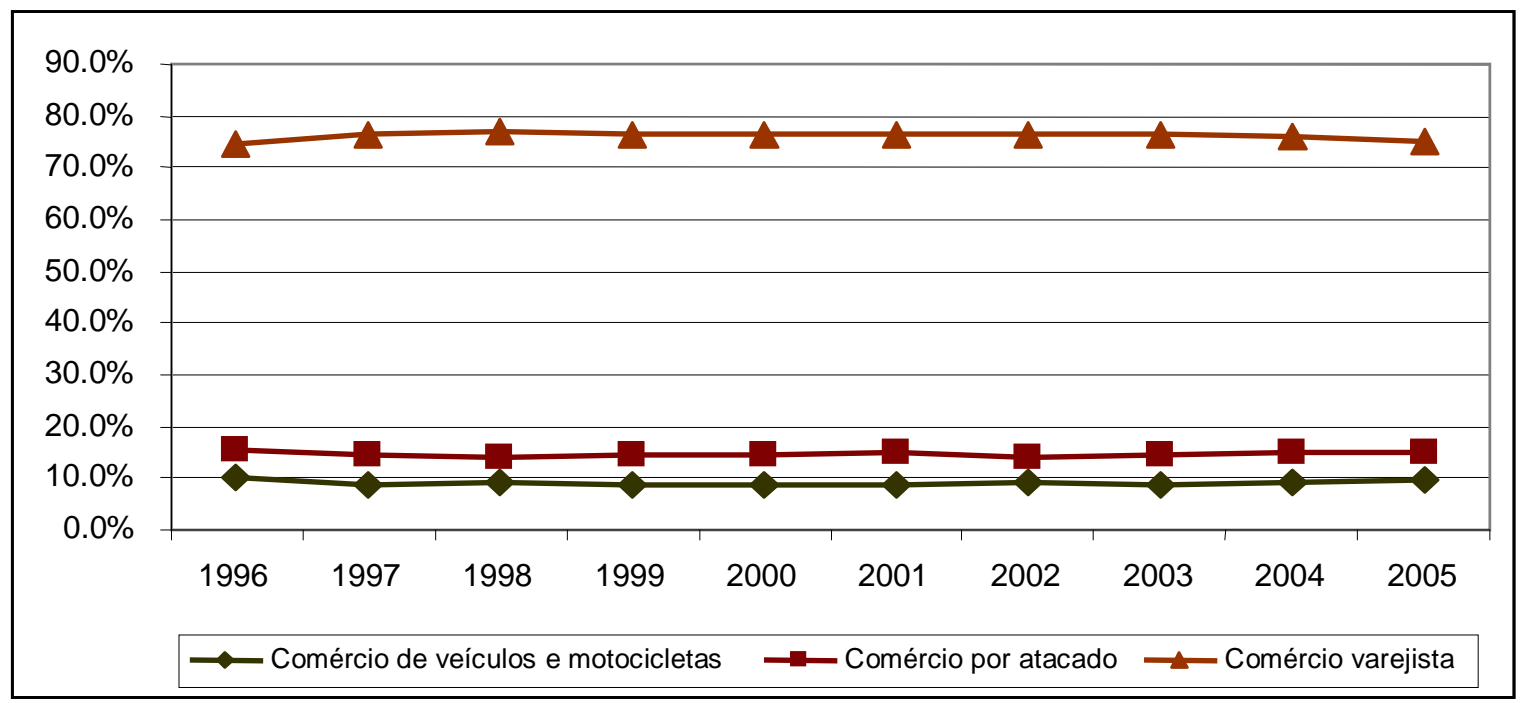

Fonte: elaboração própria a partir da pesquisa anual do comércio (IBGE)

Considerando a evolução do salário relativo do segmento comercial em relação ao salário do segmento de combustíveis ${ }^{16}$ (gráfico 5), que faz parte do segmento do comércio de produtos intermediários, resíduos e sucatas, percebe-se que a média salarial mais baixa é o do comércio varejista, representando uma menor produtividade desse segmento em relação aos demais. Desse modo, o segmento com menor produtividade é justamente o que emprega mais pessoas; cerca de 75\% (gráfico 4). Outro fato notável é a expressiva queda do salário relativo médio do segmento de comércio de veículos e motocicletas (gráfico 5).

O comércio de veículos e motocicletas, por sua vez, é subdividido em: 1) veículos automotores; 2) peças e veículos; e 3) motocicletas, peças e acessórios. De acordo com a evolução de cada um desses segmentos, apresentadas no Gráfico 6, pode-se destacar a perda de participação das pessoas empregadas no segmento de veículos automotores que passou de $4,4 \%$ para $2,95 \%$ entre $1996-2005$.

16 Os salários correspondem a soma de salários, retiradas e outras remunerações. A comparação foi feita com o segmento de combustíveis, pois este representa o segmento com maior nível salarial. Este faz parte da composição do segmento do comércio de produtos intermediários, resíduos e sucatas, que, por sua vez, faz parte da composição do comércio por atacado. 
Gráfico 5. Evolução do salário relativo do segmento comercial no Brasil: 1996-2005

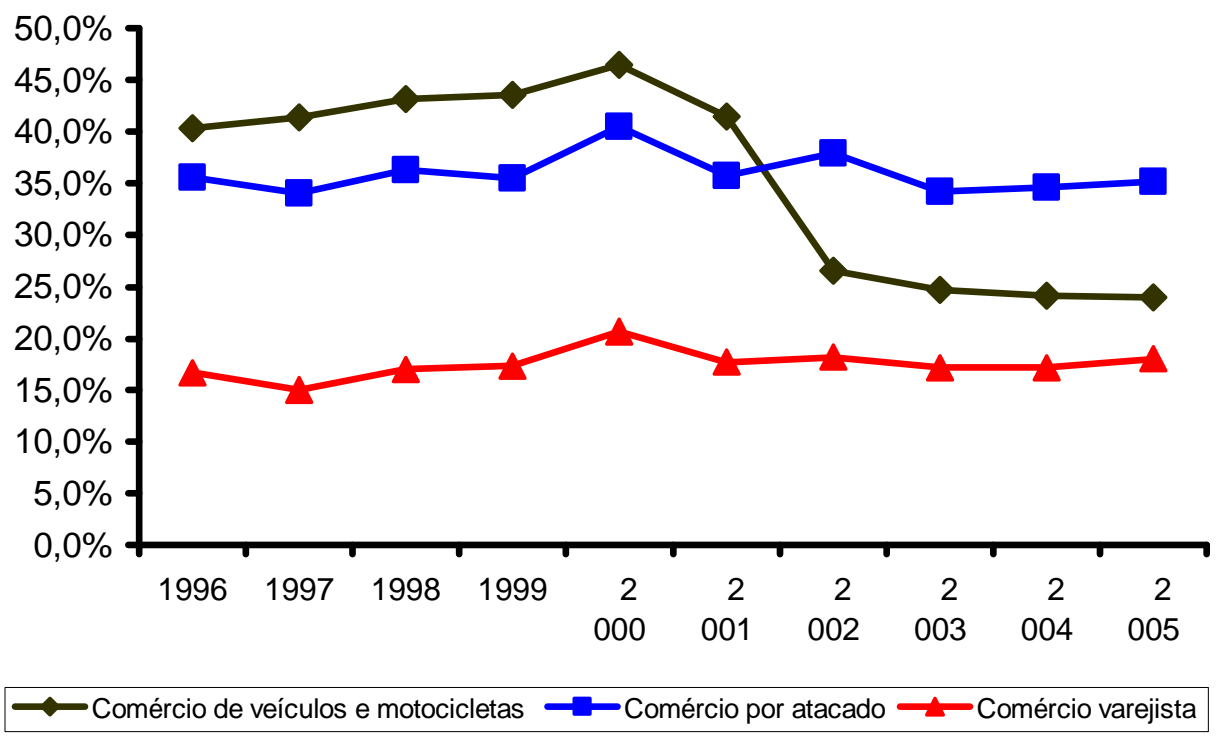

Fonte: elaboração própria a partir da pesquisa anual do comércio (IBGE)

Gráfico 6. Evolução do emprego formal no segmento de comércio de veículos e motocicletas: 1996-2005

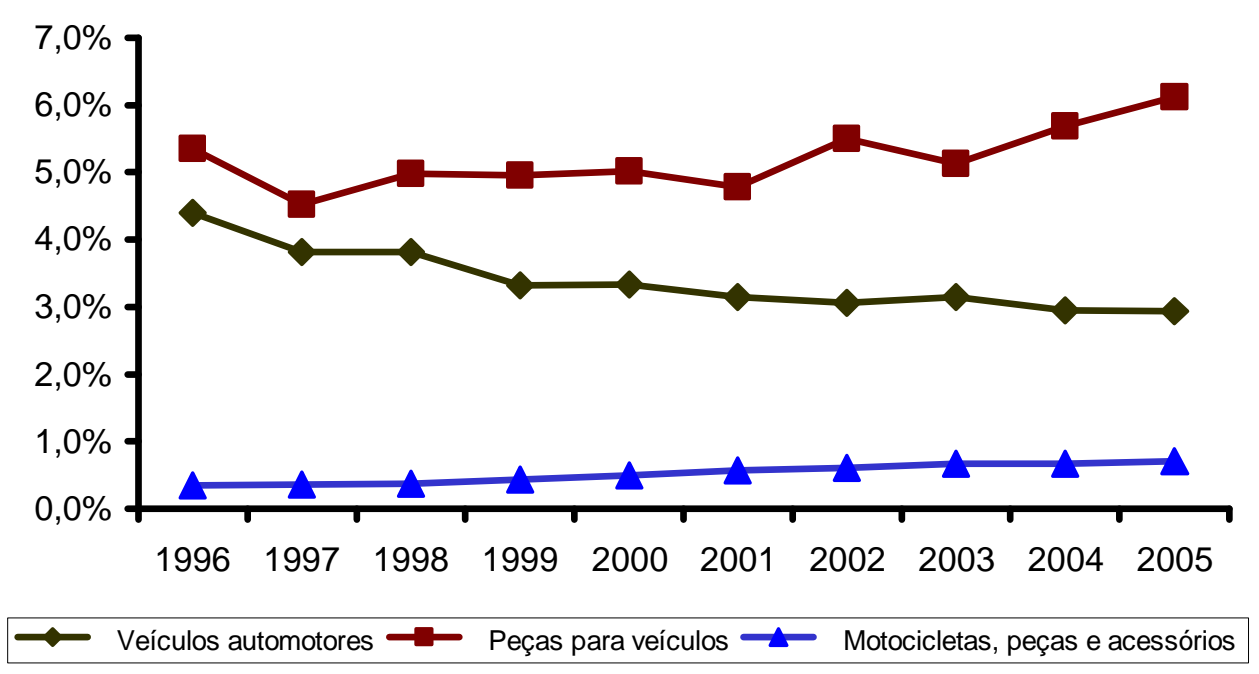

Fonte: elaboração própria a partir da pesquisa anual do comércio (IBGE)

Essa maior perda de participação das pessoas empregadas no segmento de veículos automotores mostra que um setor considerado mais dinâmico está perdendo participação no comércio de veículos e motocicletas. Assim, a mudança estrutural do comércio de veículos e motocicletas foi prejudicial à sua produtividade.

De acordo com a evolução do salário relativo desses segmentos (gráfico 7), podemos ver que o mais elevado é o de veículos automotores, representando uma maior nível de produtividade deste, apesar da queda apresentada a partir do ano 2000. O nível relativo de 
salários dos outros dois segmentos é praticamente o mesmo, representando um nível similar de produtividade.

\section{Gráfico 7. Evolução do salário relativo do segmento de comércio de veículos e motocicletas: 1996-2005}

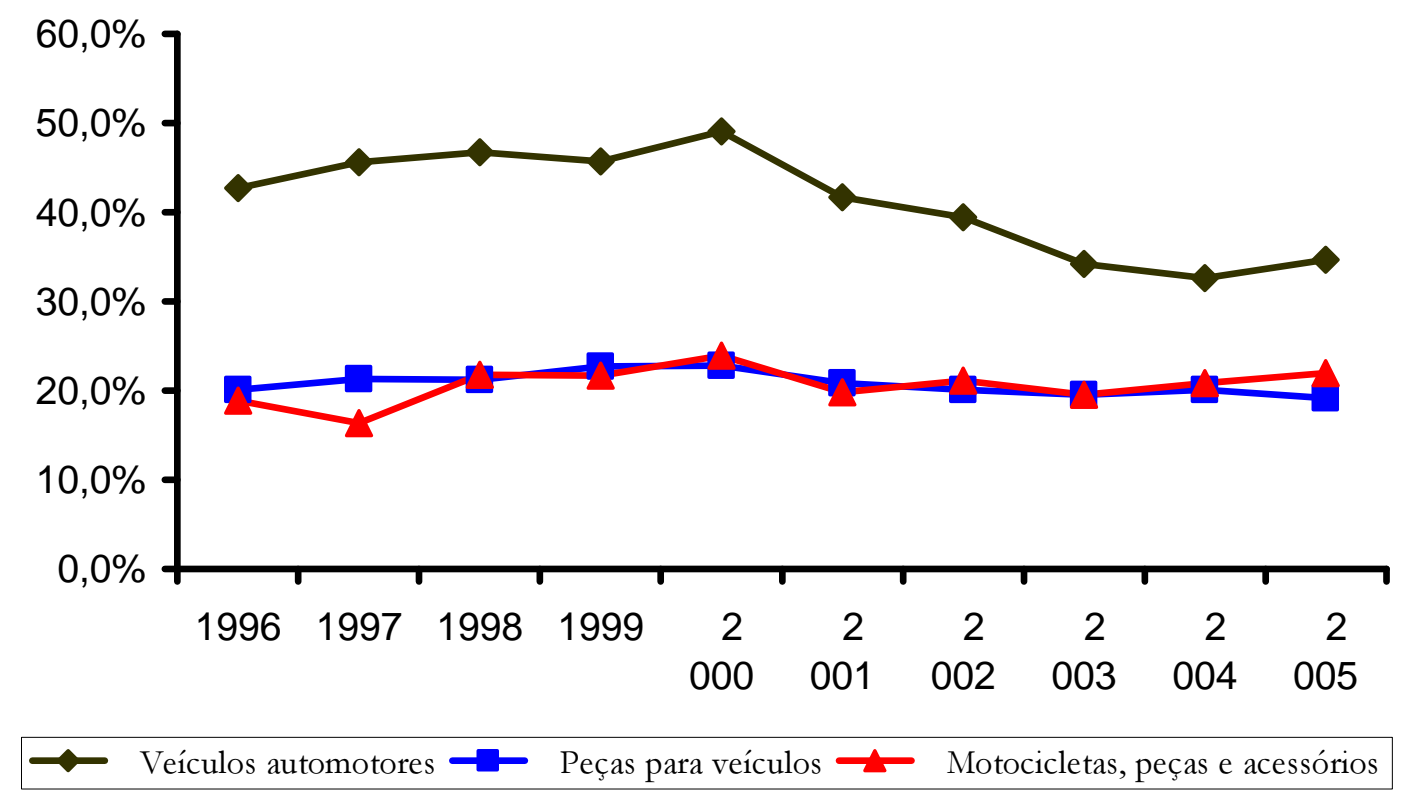

Fonte: elaboração própria a partir da pesquisa anual do comércio (IBGE)

Considerando a evolução do comércio por atacado, ocorreu uma grande perda relativa no emprego do segmento de produtos alimentícios, bebidas e fumo, passando de 5,7\% para 4,0\% da participação do emprego comercial, entre 1996 e 2005 (gráfico 8). Essa perda de participação significa uma criação líquida de 17.858 empregos. Todos os outros ganharam ou mantiveram sua participação relativa, no período de análise. 


\section{Gráfico 8. Evolução do emprego formal no segmento} de comércio por atacado: 1996-2005

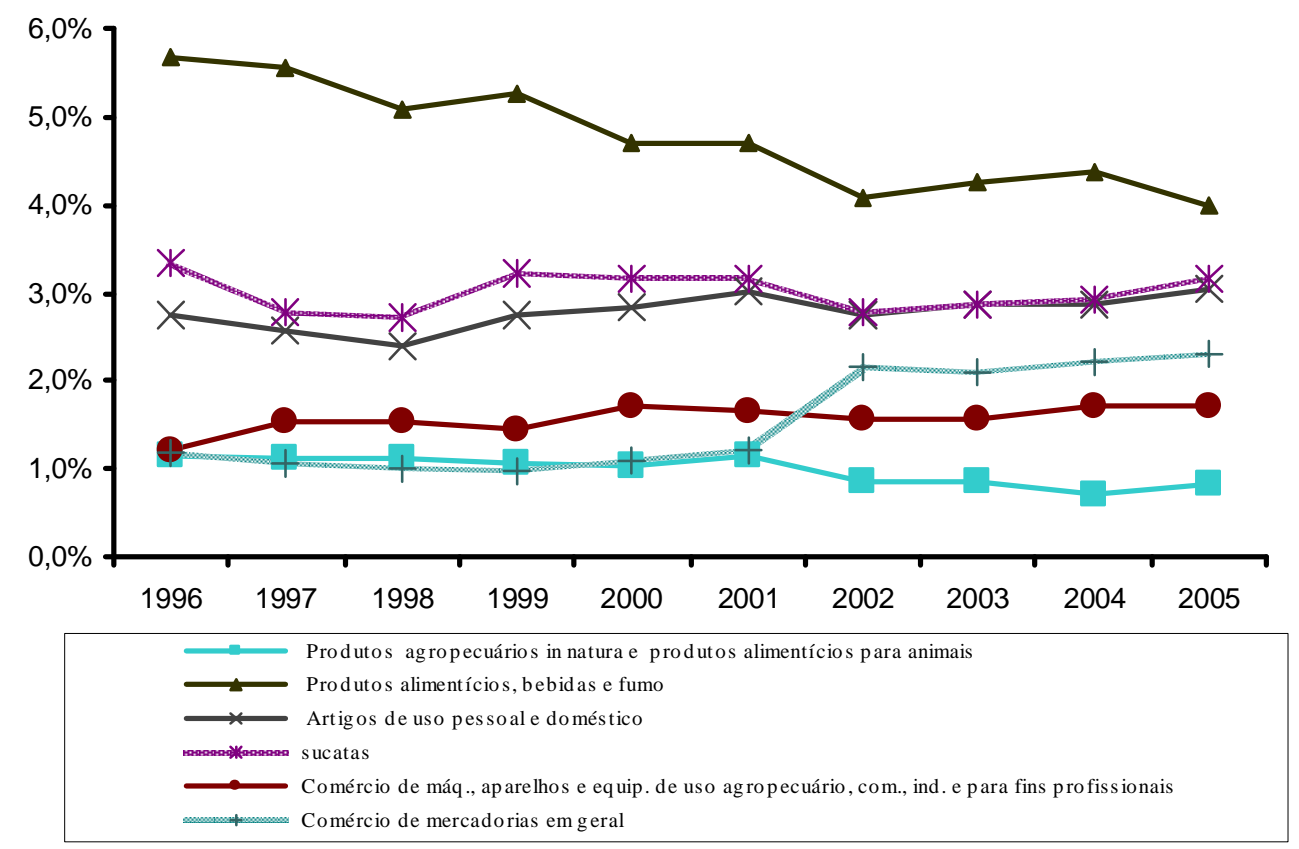

Fonte: elaboração própria a partir da pesquisa anual do comércio (IBGE)

O segmento que apresentou maior ganho de participação do emprego foi o de comércio de mercadorias em geral $(1,2 \%$ para 2,3\%), com a criação de 107.197 novos empregos. Em seguida vem o segmento de comércio de máquinas, aparelhos e equipamentos de uso agropecuário, comercial, industrial e para fins profissionais, que tinha uma participação, passando de 1,2\% para 1,7\%, entre 1996-2005. A criação de empregos nesse segmento foi de 65.222. O ganho de participação desse segmento representa, em parte, o crescimento da agronegócio brasileiro e o crescimento da demanda internacional por produtos agrícolas.

De acordo com os dados apresentados no gráfico 9, o segmento que mais perdeu participação relativa no emprego dos segmentos do comércio por atacado - o de produtos alimentícios, bebidas e fumo - é o mesmo que tem um menor nível salarial relativo. Adicionalmente, o segmento que ficou em segundo lugar no quesito ganho de participação de emprego - o de comércio de máquinas, aparelhos e equipamentos de uso agropecuário, comercial, industrial e para fins profissionais - é o que apresenta maior nível de salário médio, ou seja, o que possui maior produtividade. 


\section{Gráfico 9. Evolução do salário relativo do segmento de comércio por atacado: 1996-2005}

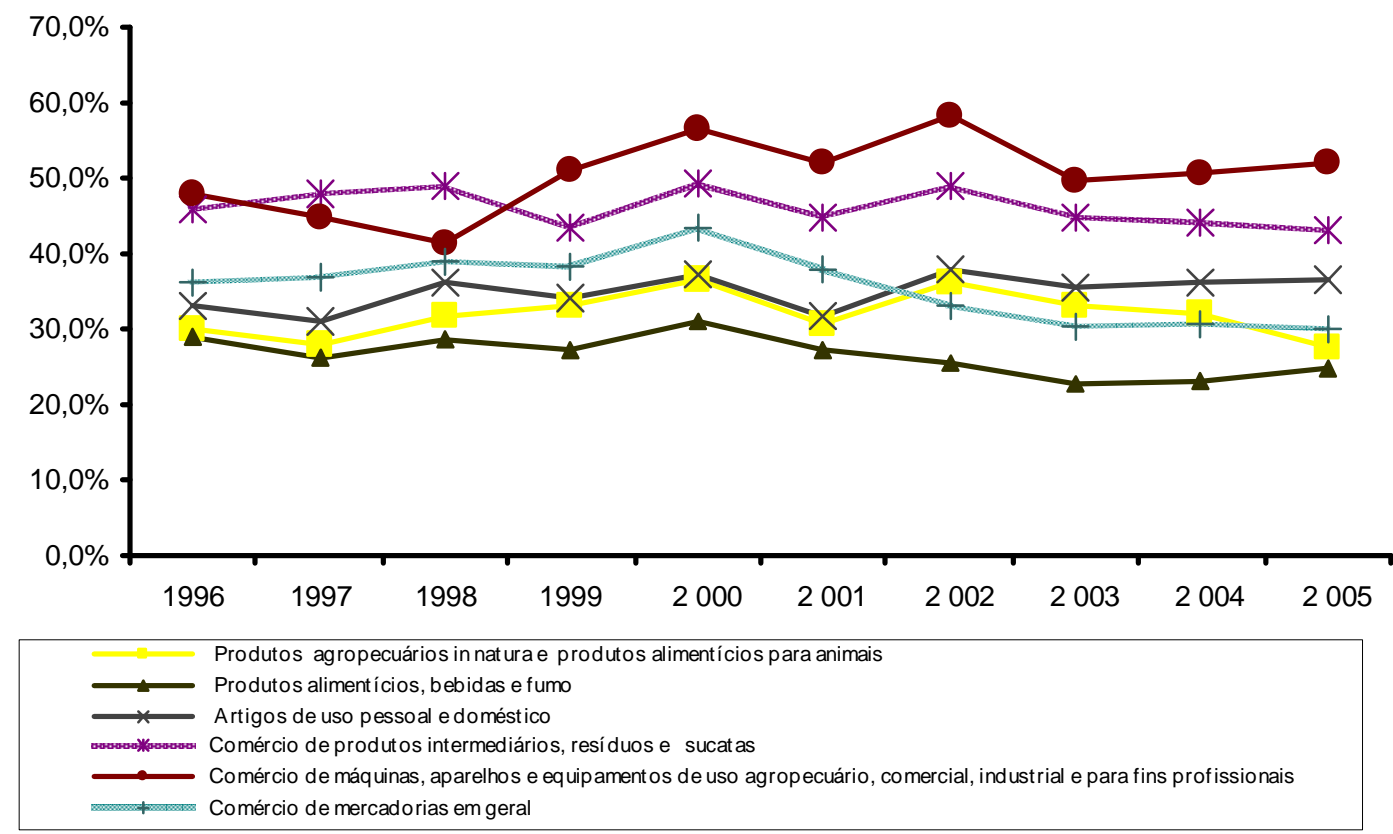

Fonte: elaboração própria a partir da pesquisa anual do comércio (IBGE)

O segmento que mais apresentou crescimento relativo em termos de emprego comércio e mercadorias em geral - tem um salário médio intermediário (gráfico 9), apesar da queda nos últimos anos. Assim, é de se esperar que sua produtividade também esteja na média do segmento do comércio por atacado.

Portanto, as mudanças de estrutura do segmento do comércio por atacado parecem ter apresentado impactos positivos sobre a produtividade deste.

No gráfico 10 é apresentada a evolução do comércio varejista brasileiro, sendo este sub-dividido em: 1) comércio não especializado; 2) tecidos, artigos de armarinho, vestuário e calçados; 3) comércio de outros produtos em lojas especializadas; 4) produtos alimentícios, bebidas e fumo; 5) combustíveis e lubrificantes17; 6) comércio de artigos usados.

Pode-se ver pelo gráfico 10 que não ocorreram grandes alterações no emprego formal do comércio varejista no período em questão. Os segmentos que mais perderam participação relativa foram o de tecidos, artigos de armarinho, vestuários e calçados $(15,7 \%$ para 14,3\%); produtos alimentícios, bebidas e fumo (8,1\% para 7,5\%); e o de comércio não especializado (18,7\% para 18,1\%), entre 1996-2005. O segmento de combustíveis e

${ }^{17}$ Foi separado de comércio não-especializado em 2002. 
lubrificantes também sofreu perda considerável (4,8\% para 3,9\%), mas no período de 2002 a 2005.

\section{Gráfico 10. Evolução do emprego formal do comércio varejista: 1996-2005}

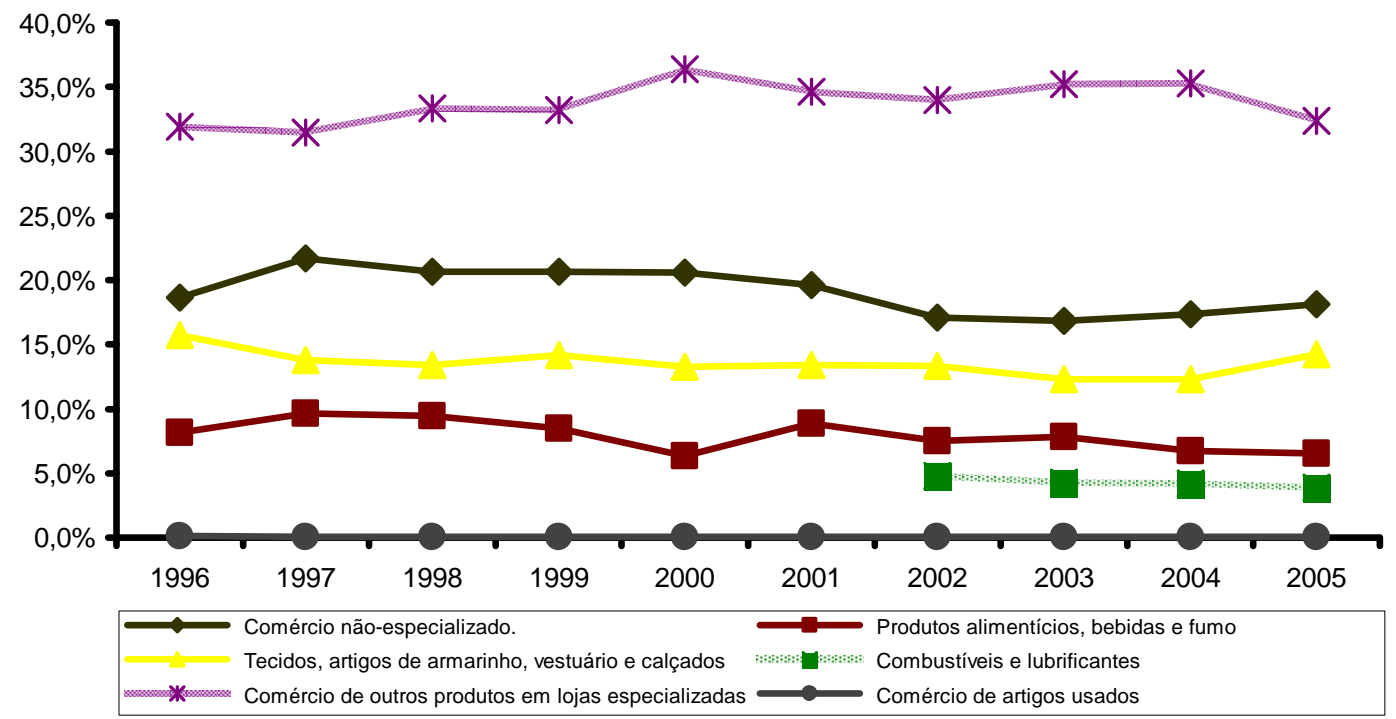

Fonte: elaboração própria a partir da pesquisa anual do comércio (IBGE)

Por outro lado, o único que ganhou participação relativa no emprego no período foi o segmento de comércio de outros produtos em lojas especializadas, cuja participação passou de $31,9 \%$ para $32,4 \%$.

Em relação à evolução do salário relativo e, conseqüentemente, da produtividade de cada segmento (gráfico 11), não fica muito claro se esse segmento ganhou ou perdeu com a mudança estrutural, pois os segmentos que perderam e ganharam participação estão entre os mais produtivos, com exceção do comércio de produtos alimentícios, bebida e fumo. 


\section{Gráfico 11. Evolução salarial relativa do segmento de comércio varejista: 1996-2005}

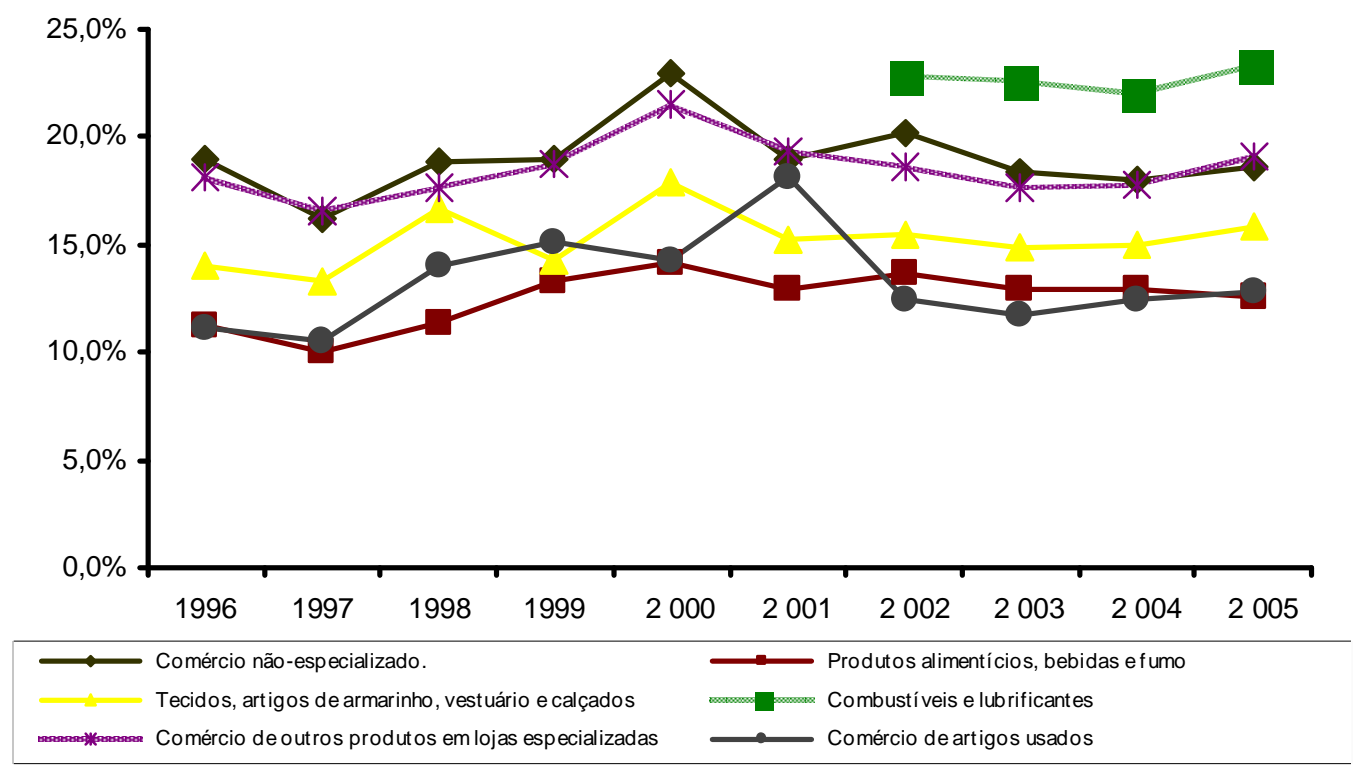

Fonte: elaboração própria a partir da pesquisa anual do comércio (IBGE)

\section{Considerações finais}

Como já detectado em alguns estudos empíricos, o país está passando por um processo de desindustrialização que se iniciou nos anos 80. Quando se define desindustrialização como uma queda na participação relativa da indústria no emprego e no valor adicionado da economia observa-se que, como em muitos outros páses, tal fenômeno também ocorre no Brasil, particularmente desde os anos oitenta. Entender as implicações desse processo do ponto de vista do crescimento e do bem-estar exige analisar onde se geram novos empregos e que acontece com a produtividade agregada da economia.

Se a perda de empregos industriais tivesse como contrapartida o aumento do emprego nos segmentos do setor de serviços que possuem grande potencial dinâmico e efeitos de encadeamento com outros setores da economia, tal processo seria natural e virtuoso. No entanto, no caso brasileiro, a perda de participação do emprego industrial não vem sendo compensando pelo ganho de participação no emprego dos segmentos do setor de serviço que sejam mais dinâmicos, de acordo com os dados apresentados no gráfico 3.

Um dos segmentos do setor de serviços que mais vem ganhando participação é o comercial. De acordo com a análise feita anteriormente, enquanto o segmento de comércio de veículos e motocicletas vem sofrendo uma perda de produtividade e o de comércio por atacado um ganho, as evidências dos ganhos de produtividade do segmento de comércio varejista não são claras. Considerando que os dois primeiros possuem uma participação 
semelhante no emprego total do segmento comercial e o último uma maior participação, os ganhos de produtividade devido a mudanças de estrutura foram baixos ou nulos.

Desse modo, a mudança estrutural pelo qual o segmento comercial vem passando desde 1996, ano em que a pesquisa anual do comércio passou a ser feita pelo IBGE, não está melhorando sua produtividade. Além disso, esse segmento não possui capacidade de servir como um motor alternativo de crescimento econômico. Assim, o ganho de participação deste no emprego total da economia brasileira está tendo impactos negativos sobre seu crescimento.

\section{Referências bibiográficas}

BAUMOL, W. "Macroeconomics of Unbalanced Growth: The Anatomy of Urban Crisis", American Economic Reriew, 57(3), pp. 415-26.

FEIJÓ, C.A.; CARVALHO, P.G.M.; RODRIGUEZ,M.S. (2003). Concentração Industrial e Produtividade do Trabalho na Indústria de Transformação nos anos 90: Evidências Empíricas. Economia: Rerista da Anpec, 4 (1): 19-52.

FURTADO, C. (1972). Análise do Modelo Brasileiro. Rio de Janeiro: Editora Civilização Brasileira, $2^{\underline{a}}$ edição.

HIRSCHMAN, A. O. (1958). The strategy of economic development. New Haven:Yale University Press.

KALDOR, N. (1957). A Model of Economic Growth. The Economic Joumal, 67 (268): 591-624.

PALMA G. (2005). Quatro fontes de desindustrialização e um novo conceito de Doença Holandesa. Trabalho apresentado na Conferência de Industrialização, Desindustrialização e Desenvolvimento, FIESP e IEDI. Centro Cultural da FIESP, 28 de Agosto de 2005.

PIEPER, U. (1998). Deindustrialization and the Social and Economic Sustainability Nexus in Developing Countries: Cross-Country Evidence on Productivity and Employment. Center for Economic Policy Analysis Working Paper, 10: 1-47. 


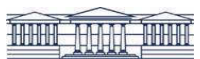

UFPR 